Haemostasis 1981;10(Suppl. 1):171

\title{
Tongue Laceration
}

\begin{tabular}{|l|l|l|}
\hline W.E.S. & & Cavalcanti \\
\hline K.M. & & da Motta \\
\hline H.M. & Monteiro & Marhino \\
\hline W. E. Santo Cavalcanti, Av. Epitacio Pessoa 2566, 22471 Lagoa, Rio de Janeiro (Brasil) \\
\hline
\end{tabular}

A large haematoma, involving the tongue, pharynx and left cheek, after tongue laceration caused by blade-like, abandoned roots of the first lower left molar tooth.

Case Report

J.B.F., a 31-year-old patient with severe haemophilia who has been the victim of bleeding episodes in the left knee and left elbow, since childhood, was admitted to our institute on August 28, 1979 with tongue bleeding, ecchymoses of the pharynx, mouth, face and neck.

The physical examination revealed: (1) marked diffuse swelling of the left side of the face and neck due to a haematoma, with ecchymoses of the gingiva and skin; (2) pharyngeal swelling; (3) limited opening of the

mouth due to swelling; (4) large swollen tongue; (5) laborious respiration due to swelling in mouth and pharynx. The following therapy was instituted: 1,000 units of concentrate of factor VIII every $12 \mathrm{~h}$. On August 29, the patient was submitted to an oral examination and the cause of the tongue laceration was found: abandoned blade-shaped roots of the first lower left molar tooth. 